\title{
Bifurcación de hopf en un modelo sobre resistencia bacteriana
}

Saulo Mosquera ${ }^{1}$, Miller Cerón ${ }^{2}$, Eduardo Ibarguen ${ }^{3}$

\section{Resumen}

En el 2011 Romero J. en su tesis de maestría "Modelos matemáticos para la resistencia bacteriana a los antibióticos" formuló y analizó un sistema no lineal de ecuaciones diferenciales ordinarias que describe la adquisición de resistencia bacteriana a través de dos mecanismos: acción de plásmidos y suministro de antibióticos. Bajo ciertas condiciones el sistema posee tres puntos de equilibrio y en uno de ellos coexisten tanto bacterias sensibles como resistentes. Simulaciones numéricas realizadas en este trabajo sugieren que alrededor de este punto de equilibrio existe una bifurcación de Hopf. A partir de estas observaciones se ha elaborado un proyecto el cual pretende analizar las condiciones que deben satisfacer los parámetros del modelo, para garantizar la existencia de esta bifurcación y clasificar su estabilidad. El objetivo central de la conferencia consiste en presentar los avances obtenidos en el desarrollo de este proyecto.

Palabras Claves: Sistemas Dinámicos, Bifurcación de Hopf, Estabilidad, Resistencia Bacteriana.

\section{Summary}

In 2011 Romero J. in his master's thesis "Mathematical models for bacterial resistance to antibiotics" formulated and analyzed a nonlinear system of ordinary differential equations describing the acquisition of bacterial resistance through two mechanisms: action plasmids and treatment with antibiotics. Under certain conditions the system has three equilibrium points and one of them coexist both sensitive and resistant bacteria. Numerical simulations performed in this work suggest that around this equilibrium point exists a Hopf bifurcation. From these observations we have developed a project which aims to analyze the conditions to be satisfied by the parameters of the model, to ensure the existence of this bifurcation and classify their stability. The main objective of the conference is to present the progress made in the development of this project.

Keywords: Dynamic Systems, Hopf bifurcation, stability, bacterial resistance.

1 Profesor Departamento de Matemáticas y Estadística, Facultad de Ciencias Exactas y Naturales, Universidad de Nariño. E-mail: samolo@ udenar.edu.co

2 Profesor Departamento de Matemáticas y Estadística, Facultad de Ciencias Exactas y Naturales, Universidad de Nariño. E-mail: millercg@ udenar.edu.co

3 Profesor Departamento de Matemáticas y Estadística, Facultad de Ciencias Exactas y Naturales, Universidad de Nariño. E-mail: edbargun@ udenar.edu.co 


\section{Introducción}

E la actualidad la resistencia bacteriana a antibióticos es uno de los problemas más graves de salud pública. El incremento de tratamientos con estos medicamentos y su uso inadecuado son la principal causa de esta emergencia.

Al respecto, la comunidad científica ha puesto de manifiesto que un mejor entendimiento de los diferentes mecanismos de adquisición de resistencia bacteriana será de gran relevancia en la prevención de infecciones y elaboración antibióticos más eficaces.

En este trabajo abordamos la adquisición de resistencia bacteriana por mutación debido a la exposición de estas a un antibiótico. Para este fin, formulamos un modelo matemático simple que describe la interacción de bacterias sensibles y resistentes a un antibiótico.

El análisis cualitativo de este modelo revela la existencia de un estado libre de bacterias, un estado endémico donde sólo existen bacterias resistentes y un estado endémico donde coexisten tanto bacterias sensibles como bacterias resistentes.

\section{FORMULACIÓN DEL MODELO}

En esta sección formulamos un modelo sobre resistencia bacteriana que describe la interacción de la población de bacterias sensibles y bacterias resistentes a cierto antibiótico. En este modelo suponemos que las bacterias sensibles adquieren resistencia por medio de dos mecanismos diferentes:

1. Mutaciones (cambios en la secuencia de bases de cromosoma) que se dan por contacto de la bacteria con el antibiótico.

2. Transmisión de plásmidos, material genético extracromosómico procedente de otras bacterias.

Para formular el modelo se consideran las siguientes variables dinámicas: población de bacterias sensibles (S), población de bacterias resistentes (R), concentración de antibióticos (C) y cantidad de plásmidos $(\mathrm{P})$. Las hipótesis sobre las que se construye el modelo son las siguientes: las bacterias sensibles así como las resistentes tienen crecimiento logístico con capacidad de carga constante (número máximo de bacterias que soporta el órgano del paciente infectado) y tasas de reproducción $\beta_{S}$ y $\beta_{r}$ con $\beta_{r} \leq \beta_{s \mid}$, respectivamente.

Las bacterias sensibles pasan a ser resistentes por mutaciones espontáneas inducidas por el antibiótico a una razón proporcional al producto de $C$ y $S$ con constante de proporcionalidad $K$ y por el contacto con plásmidos a una razón proporcional al producto de $P$ y $S$ con constante de proporcionalidad $\delta$. Las bacterias sensibles son eliminadas por acción del antibiótico a una razón proporcional al producto entre $C$ y $S$ con constante de proporcionalidad $\alpha_{S}$ y mueren a una tasa per cápita constante $\mu_{S}$. Tanto las bacterias sensibles como las resistentes son eliminadas por el sistema inmune a una tasa per cápita $\gamma$. Las bacterias resistentes mueren a una tasa per cápita constante $\mu_{r}$. Por otro lado, los plásmidos se reproducen a una tasa per cápita constante $\sigma_{p}$ y mueren a una tasa per cápita constante $\mu_{p}$.

Finalmente, la concentración de antibiótico se suministra a una tasa constante $\Lambda$, y se degrada a una tasa per cápita constante $\mu_{c}$.

Bajo estas condiciones se obtiene el siguiente sistema no lineal de ecuaciones diferenciales ordinarias:

$$
\begin{aligned}
& \frac{d S}{d t}=\beta_{S} S\left(1-\frac{S+R}{K}\right)-\left(\bar{q}+\bar{\alpha}_{S}\right) C S-\bar{\delta} P S-\gamma S-\mu_{S} S \\
& \frac{d R}{d t}=\beta r R\left(1-\frac{S+R}{K}\right)-\bar{q} C S+\bar{\delta} P S-\gamma S-\mu_{r} R \\
& \frac{d P}{d t}=\sigma_{p} R-\mu_{p} P \\
& \frac{d C}{d t}=\Lambda-\mu_{c} C
\end{aligned}
$$

\section{SOLUCIONES DE EQUILIBRIO}

Al igualar a cero el lado derecho del sistema de ecuaciones de ecuaciones diferenciales anterior y resolver el sistema algebraico de ecuaciones se obtiene que posee tres puntos de equilibrio como lo muestra el siguiente resultado. 
Proposición: Para todos los valores de los parámetros el sistema anterior siempre tiene el equilibrio trivial

$$
P_{0}=(0,0,0,1)
$$

Si $R_{r}>1$ además de $P_{0}$ existe el equilibrio

$$
P_{1}=\left(0, r_{1} \frac{r_{1}}{\mu_{p}}, 1\right)
$$

Si $\quad S_{0}>1$ y $r_{1}<r_{\max }$, además de $P_{0}$ existe un equilibrio donde coexisten bacterias sensibles y resistentes

$$
P_{2}=\left(s_{2}, r_{2}, p_{2}, 1\right)
$$

y los valores de las coordenadas de esos puntos de equilibrio están determinadas por relaciones entre los parámetros del modelo.

\section{ESTABILIDAD.}

En cuanto a la estabilidad asintótica local de las soluciones de equilibrio se tiene el siguiente resultado.

Proposición: Si $R_{r}>1 \mathrm{y}, r_{1}<r_{\max }$ entonces el equilibrio trivial $P_{0}$ es localmente asintóticamente estable en la región en la cual el sistema tiene sentido biológico.

$\mathrm{Si}, r_{1}<r_{\max }$ entonces $P_{1}$ es inestable.

\section{BIFURCACIÓN DE HOPF}

En esta sección, se tratará la existencia de una bifurcación de Hopf para el sistema de ecuaciones diferenciales considerado alrededor del equilibrio endémico $P_{2}$. En este sentido se tiene el siguiente resultado.

\section{PROPOSICIÓN:}

Cuando se toma como parámetro de bifurcación $\beta_{s}$ la matriz Jacobiana, alrededor del punto de equilibrio $P_{2}$, del sistema de ecuaciones diferenciales definido anteriormente posee dos valores propios imaginarios puros para cierto valor del parámetro $\beta_{s}^{0}$ y la velocidad de cruce, es decir:

$$
\frac{d \operatorname{Re}\left(\lambda\left(\beta_{s}\right)\right)}{d \beta}
$$

Evaluada en $\beta_{s}^{0}$ es diferente de cero.

\section{Conclusiones}

El objetivo básico de este trabajo fue el de formular y analizar un sistema no lineal de ecuaciones diferenciales entre modela la adquisición de resistencia bacteriana por mutación debido a la exposición de estas a un antibiótico. Este sistema posee tres puntos de equilibrio para el cual se estudia su estabilidad local, en particular alrededor de uno de estos puntos la matriz jacobiana posee dos valores propios imaginarios puros y en este punto de equilibrio se demuestra la existencia de una bifurcación de Hopf, sin embargo no fue posible clasificar su estabilidad y adicionalmente no se abordaron las implicaciones de carácter biológico que esto pudiese tener en el fenómeno en cuestión.

\section{Bibliografía}

Alvarez-Ramírez J., Avendaño J., Esteva L., Flores J., Fuentes-Allen J., Gómez G. and Estrada J., within-host population dynamics of antibiotic-resistant M. tuberculosis, Math. And Bio, J, 64(2007), pp. 35-67.

Guilfoile, P. Deadl and Epidemic; antibiotic-Resistant Bacteria, Chelsea House Publisher U. K., 2007.

Kuztnezof, Y. Elements of applied Bifurcation Theory $2^{\circ}$ edición Springer-verlag. New York. 1998.

Romero J. P., Modelos Matemáticos para la resistencia Bacteriana a los antibióticos. Tesis de Maestría. Universidad de Quindío. 